\title{
BMJ Open Predictors of frailty among Chinese community-dwelling older adults with type 2 diabetes: a cross-sectional survey
}

\author{
Linglin Kong (D) , ${ }^{1,2}$ Huimin Zhao, ${ }^{1}$ Junyao Fan, ${ }^{1}$ Quan Wang, ${ }^{1}$ Jie Li, ${ }^{1}$ Jinbing Bai, ${ }^{3}$ \\ Jing Mao (1) 1
}

To cite: Kong L, Zhao H, Fan J, et al. Predictors of frailty among Chinese communitydwelling older adults with type 2 diabetes: a crosssectional survey. BMJ Open 2021;11:e041578. doi:10.1136/ bmjopen-2020-041578

- Prepublication history for this paper is available online. To view these files, please visit the journal online (http://dx.doi. org/10.1136/bmjopen-2020041578).

Received 15 June 2020 Revised 11 December 2020 Accepted 29 December 2020

Check for updates

(C) Author(s) (or their employer(s)) 2021. Re-use permitted under CC BY-NC. No commercial re-use. See rights and permissions. Published by BMJ.

${ }^{1}$ School of Nursing, Tongji Medical College, Huazhong University of Science and Technology, Wuhan, China

${ }^{2}$ School of Nursing, Hubei University of Science and Technology, Xianning, China ${ }^{3}$ Nell Hodgson Woodruff School of Nursing, Emory University, Atlanta, Georgia, USA

Correspondence to Associate Professor Jie Li; lijie@hust.edu.cn and Professor Jing Mao; maojing@hust.edu.cn

\section{ABSTRACT}

Objectives To assess the prevalence of frailty and identify predictors of frailty among Chinese community-dwelling older adults with type 2 diabetes.

Design A cross-sectional design.

Setting Two community health centres in central China. Participants 291 community-dwelling older adults aged $\geq 65$ years with type 2 diabetes.

Main outcome measures Data were collected via face-to-face interviews, anthropometric measurements, laboratory tests and community health files. The main outcome measure was frailty, as assessed by the frailty phenotype criteria. The multivariate logistic regression model was used to identify the predictors of frailty.

Results The prevalence of prefrailty and frailty were $51.5 \%$ and $19.2 \%$, respectively. The significant predictors of frailty included alcohol drinking (ex-drinker) (OR 4.461, $95 \% \mathrm{Cl} 1.079$ to 18.438), glycated haemoglobin (OR 1.434, $95 \% \mathrm{Cl} 1.045$ to 1.968 ), nutritional status (malnutrition risk/malnutrition) (OR $8.062,95 \% \mathrm{Cl} 2.470$ to 26.317 ), depressive symptoms (OR $1.438,95 \% \mathrm{Cl} 1.166$ to 1.773 ) and exercise behaviour (OR $0.796,95 \% \mathrm{Cl} 0.716$ to 0.884 ). Conclusions A high prevalence of frailty was found among older adults with type 2 diabetes in the Chinese community. Frailty identification and multifaceted interventions should be developed for this population, taking into consideration proper glycaemic control, nutritional instruction, depressive symptoms improvement and enhancement of self-care behaviours.

\section{INTRODUCTION}

Across the world, the estimated number of people aged 65-99 years with diabetes was 136 million (19.3\%) in 2019, and this number is estimated to increase to 195 million in 2030 and 276 million in $2045 .^{1}$ China had the world's largest number of adults with diabetes, ${ }^{1}$ and the prevalence of older Chinese adults with diabetes over the age of 60 was $20.2 \%$ in the latest national survey. ${ }^{2}$ Elderly people with type 2 diabetes are at risk for developing frailty, ${ }^{3}$ a geriatric syndrome manifesting as a reduction in one's physical strength, endurance and physiological function that increases the likelihood of developing functional dependency and death. ${ }^{4}$
Strengths and limitations of this study

- The study evaluated an extensive list of sociodemographic factors, lifestyle and clinical characteristics, nutritional status, depressive symptoms and diabetes self-care behaviours that could influence the frailty status of community-dwelling older adults with type 2 diabetes.

- The study examined which domains of diabetes self-care behaviours were associated with frailty among diabetic older adults.

- The study is a cross-sectional study, so a causal relationship between factors associated with frailty could not be established.

- The study was conducted in one city of China, which may affect the generalisability of the findings.

Diabetic people are more likely to be frail than their non-diabetic counterparts. ${ }^{56}$ This relationship between diabetes and frailty may be explained by the fact that diabetes impairs skeletal muscle function, vascular function and hormonal milieu, as well as accelerates sarcopenia, thereby leading to increased frailty. ${ }^{378}$

Frailty is associated with higher disability, mortality, cardiovascular events and healthcare utilisation among older adults with type 2 diabetes. ${ }^{9}{ }^{10}$ Identifying the associated factors for frailty among older adults with diabetes may help to improve their health outcomes. A few studies have shown that sociodemographic factors (eg, age, education level), ${ }^{6} 11$ physical factors (eg, systolic blood pressure, bodyweight, abdominal obesity) ${ }^{6} 11{ }^{12}$ and biological factors (eg, glycated haemoglobin (HbA1c), albumin, high-density lipoprotein cholesterol ${ }^{611}$ were associated with frailty in diabetic older adults. Until now, important, modifiable factors such as nutritional status, psychological well-being and self-care behavioural factors were rarely studied among community-dwelling diabetic older adults. 
The association between malnutrition and frailty has been established among community-dwelling older adults. ${ }^{1314}$ Depression is another common factor associated with frailty among the elderly. ${ }^{1516}$ However, there is a lack of understanding of the impact of malnutrition and depression on frailty among the specific diabetic older population. Diabetic older adults should adopt numerous diabetes self-care behaviours to control their disease; these behaviours include proper diet, regular exercise, self-monitoring of blood glucose, proper foot care and strict adherence to prescribed medications. ${ }^{17}$ Nevertheless, there is a dearth of studies on which domains of diabetes self-care behaviours are preferentially associated with frailty. Examining these associations is important for developing specific interventions to reduce the risk of frailty for diabetic older people.

In China, there is an increasing number of older people with type 2 diabetes living in the community, and the health management of the diabetic elderly population is the focus of many community health services; however, frailty is not among the physical conditions that is routinely screened for in this population. ${ }^{18}$ Little is known about the frailty status among the communitydwelling older adults with type 2 diabetes in China. To our knowledge, only one study reported the prevalence of frailty in a community-dwelling diabetic population in mainland China; however, that study included a sample of diabetic people aged 55 years and older, identifying the risk factors of frailty among an elevated blood glucose (pre-diabetes and diabetes) population. ${ }^{5}$ Therefore, the aims of this study were to assess the prevalence of frailty and explore the predictors of frailty among Chinese community-dwelling older adults with type 2 diabetes.

\section{METHODS}

\section{Study design and setting}

A cross-sectional design was used. The participants were recruited from two community health centres of Xianning City of Hubei Province in China from June to October 2019. Both community health centres provided primary healthcare services for older people in urban and rural communities.

\section{Data collection and ethical considerations}

The researcher contacted the directors of two community health centres and explained the aims of this study. After permission was granted, the public health nurses and physicians were invited to assist with data collection. Health centre staff helped to recruit participants by phone, informing the eligible diabetic older adults of the study purpose. Eligible individuals were then invited to the community health centres to complete the survey if they consented to participate. As another means of recruitment, when older adults with type 2 diabetes went to the community health centres for a physical check-up, follow-up blood glucose monitoring, or health education, they were also invited to participate in this study, if eligible. Once the written informed consent was obtained from each participant, the survey was administered by trained investigators. The information in this survey was obtained from the participants' self-reporting, anthropometric measurements, and laboratory test results, which were supplemented by the community health files.

\section{Participants}

Older adults with type 2 diabetes were identified from the electronic files of the two community health centres. The inclusion criteria of this study were as follows: (1) at least 65 years old and living in the community; (2) diagnosed with type 2 diabetes, as confirmed by a physician based on the WHO diagnostic criteria, 1999; (3) received their diagnosis at least 6 months prior to joining the study. The diabetic older adults were excluded if they: (1) could not walk independently; (2) had severe vision and hearing problems; (3) were unable to communicate with the investigators; (4) had dementia or mental health disorders and (5) had acute diabetic complications.

The sample size was calculated using the formula for cross-sectional studies, ${ }^{19} n=\frac{Z^{2} P(1-P)}{d^{2}}$. Where $\mathrm{n}$ is the sample size, $\mathrm{Z}$ is the statistic corresponding to level of confidence, $\mathrm{P}$ is expected prevalence, and $\mathrm{d}$ is precision. We assumed a confidence level of $95.0 \%$, expected frailty prevalence of $20.0 \%$ for community-dwelling older adults with type 2 diabetes (determined by the presurvey), and precision of $5.0 \%$, indicating that at least 246 participants were needed for this study.

\section{Survey instrument}

The personal information questionnaire was used to collect the participants' characteristics. The sociodemographic characteristics included age, gender, living place, education level, marital status, living status, working status, personal monthly income and medical insurance; the lifestyle and clinical characteristics included smoking, alcohol drinking, sleep duration at night, self-rated quality of sleep, duration of diabetes, number of comorbidities, polypharmacy, body mass index (BMI), waist circumference and HbAlc. Smoking status was categorised as current smoker (having smoked at least one cigarette per day), ex-smoker (having stopped smoking at least 1 year before the survey) and non-smoker (having never smoked in one's lifetime). Alcohol drinking status was categorised into current drinker (someone who reported consuming alcohol currently), ex-drinker (someone who had quitted drinking at least 1 year prior to the survey) and non-drinker (someone who reported never consuming alcohol). Polypharmacy was defined as concurrent use of five or more drugs. BMI was calculated by weight $(\mathrm{kg}) /$ (height $(\mathrm{m}))^{2}$ and classified as underweight, normal, overweight and obese $(<18.5,18.5-23.9,24.0-27.9$ and $\geq 28.0 \mathrm{~kg} / \mathrm{m}^{2}$ ), and high waist circumference was defined as $\geq 85 \mathrm{~cm}$ in men and $\geq 80 \mathrm{~cm}$ in women. ${ }^{20}$

Frailty was measured using the modified frailty phenotype criteria, which was based on the phenotypic criteria proposed by Fried et $a l^{21}$ The criteria included five 
components: (1) unintentional weight loss: weight loss $\geq 4.5 \mathrm{~kg}$ in the past year, not due to dieting and exercise; (2) exhaustion: It was identified based on a response of '3-4 days or most of the time' during the week to either of the two questions: 'I felt that everything I did was an effort' and 'I could not get going'; (3) Slowness: average walking speed was tested by asking the participants to walk $6 \mathrm{~m}$ at their usual pace, at total of two times. Slowness was identified by walking speed for men $(\leq 0.89 \mathrm{~m} / \mathrm{s})$ and women $(\leq 0.79 \mathrm{~m} / \mathrm{s})^{22}$; (4) Weakness: grip strength was measured with a dynamometer three times on each hand, and the maximum of the readings was used. Weakness was judged by grip strength for men $(\leq 28 \mathrm{~kg})$ and women $(\leq 18 \mathrm{~kg})^{22}$ and (5) low physical activity: the Chinese version of Physical Activity Scale for the Elderly (PASE) ${ }^{23}$ was used to assess participants' physical activity level in the past week. Low physical activity was classified by PASE score for men $(\leq 56.4)$ and women $(\leq 58.8) .{ }^{22}$ One point was assigned for the presence of each component, and the summed score was used to classify participants as robust (score $=0$ ), prefrail $($ score $=1-2)$ and frail $($ score $=3-5)$.

Mini-Nutritional Assessment (MNA) was used to assess the nutritional status of older adults. ${ }^{24}$ It consists of 18 items grouped into four parts: anthropometric assessment, general assessment, dietary assessment and selfassessment. The total score ranges from 0 to 30 and is used to classify the elderly as well-nourished $(\geq 24)$, at risk of malnutrition (17-23.5) or malnourished $(<17)$. The Chinese version of MNA has been proven to be reliable and valid in the community-dwelling older population. ${ }^{25}$

Geriatric Depression Scale-15 (GDS-15) was used to evaluate the depressive symptoms of older adults. ${ }^{26}$ The scale contains 15 items that require the subjects to answer with 'yes' or 'no'. The maximum score of the scale is 15 , and a higher score indicates more severe depressive symptoms. The Chinese version of GDS-15 is a reliable and valid screening tool for assessing geriatric depressive symptoms in the Chinese population. ${ }^{27}$

The Chinese version of Summary of Diabetes SelfCare Activities (SDSCA) ${ }^{28}$ was used to measure self-care behaviours of the older adults with type 2 diabetes; this instrument was modified from the original SDSCA. ${ }^{17}$ It is a brief self-report questionnaire that includes 11 items assessing the following aspects: general diet, specific diet, exercise, blood-glucose testing, foot care and medication care in the past week. The total score of this scale ranges from 0 to 77, and a higher score indicates better diabetes self-care behaviours. It showed good validity and testretest reliability in Chinese patients with type 2 diabetes. ${ }^{28}$

Anthropometric measurements, including height or knee height, weight, mid-arm circumference, calf circumference and waist circumference, were measured by the trained investigators according to the measurement manual. Knee height was measured and converted to the estimated height using specific equations ${ }^{29}$ for the older adults with severe spinal curvature. All the HbAlc measures were obtained after the participants were recruited into the study. The blood collection and HbAlc measurements were administered by the community health centre laboratories when the participants came to the centres for this survey.

\section{Data analysis}

The SPSS V.21.0 (SPSS) was used for data analysis. Frailty was defined as the dependent variable with $1=$ robust ( 0 on the frailty phenotype criteria), $2=$ prefrail (1-2), $3=$ frail $(\geq 3)$. Sociodemographic, lifestyle and clinical characteristics, malnutrition, depressive symptoms and diabetes self-care behaviours were considered potential factors for frailty. Raw data were evaluated for normality and multicollinearity before data analysis. Data were described as n (\%) for categorical variables and median $(\mathrm{IQR})$ or mean $\pm \mathrm{SD}$ for continuous variables. To test the statistical difference among groups, univariate analyses were conducted using $\chi^{2}$ test for categorical variables and Kruskal-Wallis $\mathrm{H}$ test for continuous variables. Variables that showed statistical significance of $p<0.1$ in the univariate analyses were included in the multinomial logistic regression, which estimated the prevalence OR for prefrail relative to robust and for frail relative to robust. The statistical significance was set at $\mathrm{p}<0.05$ for the logistic regression.

\section{Patient and public involvement}

Patients were not involved in the development of research question or the design of the study. Anthropometric measurements and $\mathrm{HbAlc}$ test results were provided to the participants, community physicians and nurses.

\section{RESULTS}

As shown in figure 1, a total of 302 eligible older adults consented to participate in this study. Eleven participants did not complete the questionnaires due to temporary issues and limited time, so the final sample consisted of 291 participants. Among these participants, 85 (29.2\%) were robust, $150(51.5 \%)$ were prefrail and $56(19.2 \%)$ were frail.

\section{Characteristics of the participants}

The median age of participants was 69 years (IQR 67-72), with a range from 65 to 85 years. Among the participants, $154(52.9 \%)$ were female. The majority of the participants were living in urban areas $(84.5 \%)$, had junior high school or higher education $(63.9 \%)$, had a spouse $(80.1 \%)$, lived with others $(86.9 \%)$, were currently not working $(92.1 \%)$, had a personal monthly income below 3000 yuan $(66.3 \%)$ and had urban employees' insurance $(58.1 \%)$ (table 1$)$.

Regarding the lifestyle characteristics, most of the participants were non-smokers $(63.6 \%)$, non-drinkers (57.4\%), with 5-8hour sleep duration at night per day $(66.0 \%)$ and had good/very good sleep quality (61.2\%) (table 2). Considering clinical characteristics, the median duration of diabetes was 10 years (IQR 4-16), and the median number of comorbidities was 5 (IQR 3-6). 


\section{Older adults with type 2 diabetes ( $\geq 65$ years) identified from the community health files, $n=960$}

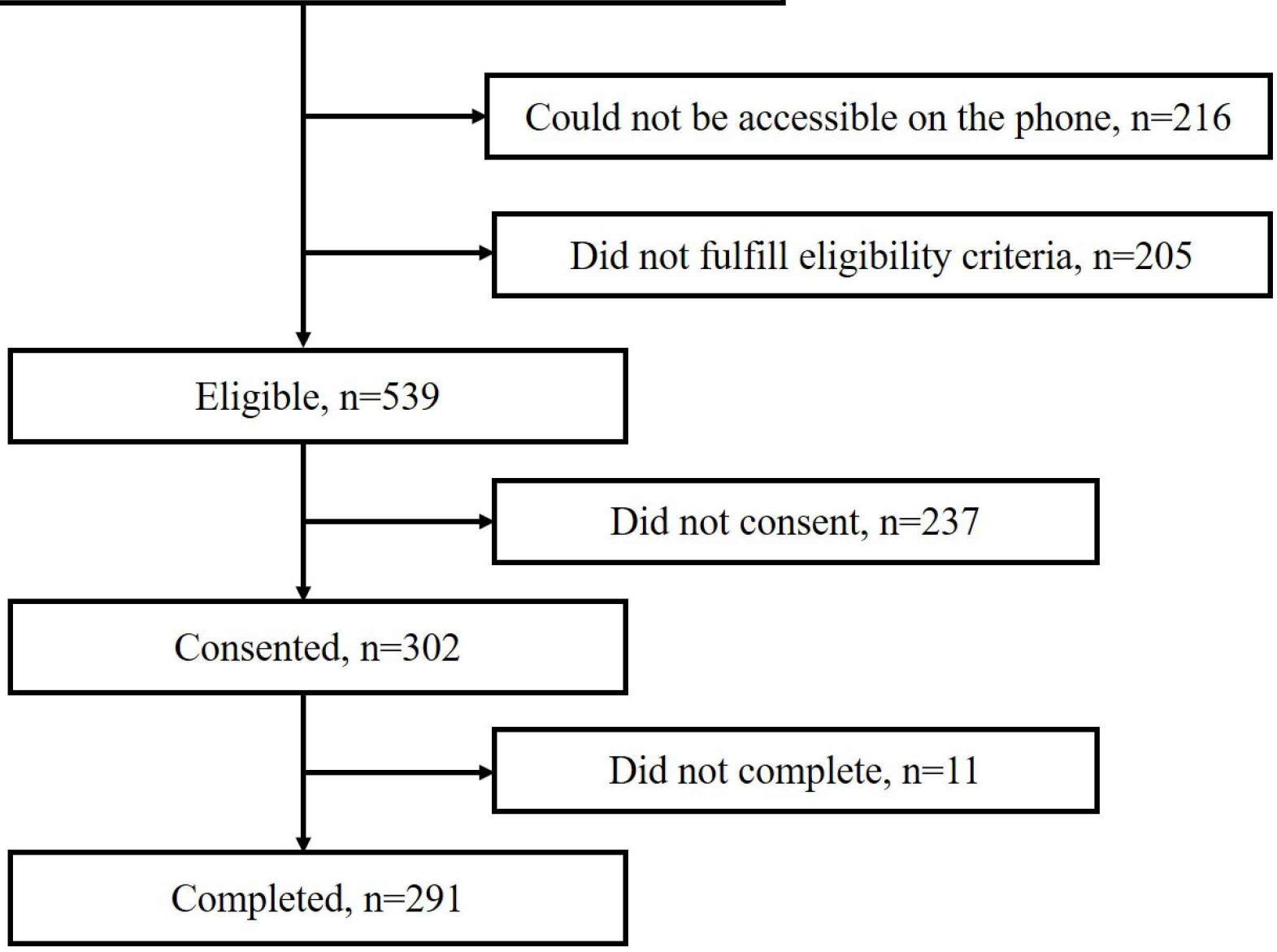

Figure 1 Flow chart of inclusion of participants.

Among all participants, 29.6\% had polypharmacy, 43.6\% had normal BMI and $17.5 \%$ had a normal waist circumference. The median score of HbAlc was $6.66 \%$ (IQR 5.87-7.47) (table 2).

\section{Malnutrition, depressive symptoms and diabetes self-care behaviours}

Of all participants, $96(33.0 \%)$ were at risk of malnutrition, $6(2.1 \%)$ were malnourished, and 189 (64.9\%) were nourished. The median score of depressive symptoms was 3 (IQR 1-5). The total score for diabetes selfcare behaviours ranged from 12 to 70 , with an average of $40.25 \pm 10.08$. Among the six subdimensions of diabetes self-care behaviours, the two dimensions with the lowest level were blood-glucose testing $(0(0-2))$ and foot care $(0(0-7))$ (table 3).

\section{Univariate analyses for influencing factors of frailty}

Univariate analyses were conducted to explore the associated factors for frailty according to the criterion of inclusion $(\mathrm{p}<0.10)$. Significant sociodemographic differences among groups were found for education level $(\mathrm{p}=0.077)$, personal monthly income $(\mathrm{p}=0.026)$ and medical insurance $(\mathrm{p}=0.034)$ (table 1$)$. Regarding the lifestyle and clinical characteristics, significant group differences included alcohol drinking $(\mathrm{p}=0.004)$, sleep duration at night $(\mathrm{p}=0.046)$, self-rated sleep quality $(\mathrm{p}=0.065)$, duration of diabetes $(\mathrm{p}=0.036)$, comorbidities $(\mathrm{p}=0.030)$, polypharmacy $(\mathrm{p}=0.025)$ and HbA1c $(\mathrm{p}=0.055)$ (table 2). As shown in table 3 , significant group differences were noted for malnutrition risk/malnutrition $(\mathrm{p}<0.001)$, depressive symptoms $(p<0.001)$, exercise $(p<0.001)$, foot care $(\mathrm{p}=0.007)$ and medication care $(\mathrm{p}=0.060)$.

\section{Predictors of frailty}

The predictors of prefrailty for older adults with type 2 diabetes in this study included alcohol drinking (ex-drinker) $(\mathrm{p}=0.017)$, malnutrition risk/malnutrition $(p=0.026)$, depressive symptoms $(p=0.003)$ and exercise $(\mathrm{p}=0.008)$ (table 4). The following predictors were found for the condition of frailty: alcohol drinking (ex-drinker) ( $\mathrm{p}=0.039)$, HbA1c $(\mathrm{p}=0.026)$, malnutrition risk/malnutrition $(\mathrm{p}=0.001)$, depressive symptoms $(\mathrm{p}=0.001)$ and exercise $(\mathrm{p}<0.001)($ table 4$)$.

\section{DISCUSSION}

In this study, we assessed frailty status and its associated factors among Chinese community-dwelling older adults 
Table 1 Sociodemographic characteristics of the participants by different frailty statuses

\begin{tabular}{|c|c|c|c|c|c|}
\hline Variables & $\begin{array}{l}\text { Total } \\
(n=291) \\
N(\%)\end{array}$ & $\begin{array}{l}\text { Robust } \\
(n=85) \\
N(\%)\end{array}$ & $\begin{array}{l}\text { Prefrail } \\
(n=150) \\
N(\%)\end{array}$ & $\begin{array}{l}\text { Frail } \\
(n=56) \\
N(\%)\end{array}$ & $P$ value \\
\hline Age (years) & & & & & 0.295 \\
\hline $65-69$ & $154(52.9)$ & $52(61.2)$ & $74(49.3)$ & $28(50.0)$ & \\
\hline $70-74$ & 91 (31.3) & 25 (29.4) & $49(32.7)$ & $17(30.4)$ & \\
\hline$\geq 75$ & $46(15.8)$ & $8(9.4)$ & 27 (18.0) & $11(19.6)$ & \\
\hline Gender & & & & & 0.270 \\
\hline Male & $137(47.1)$ & 41 (48.2) & 75 (50.0) & $21(37.5)$ & \\
\hline Female & $154(52.9)$ & $44(51.8)$ & $75(50.0)$ & $35(62.5)$ & \\
\hline Living place & & & & & 0.434 \\
\hline Urban & $246(84.5)$ & 75 (88.2) & $126(84.0)$ & 45 (80.4) & \\
\hline Rural & 45 (15.5) & $10(11.8)$ & $24(16.0)$ & $11(19.6)$ & \\
\hline Education level & & & & & 0.077 \\
\hline Illiterate & $42(14.4)$ & $8(9.4)$ & $18(12.0)$ & $16(28.6)$ & \\
\hline Elementary school & $63(21.6)$ & $18(21.2)$ & $34(22.7)$ & $11(19.6)$ & \\
\hline Junior high school & 95 (32.6) & 27 (31.8) & 50 (33.3) & $18(32.1)$ & \\
\hline Senior high school & 55 (18.9) & 19 (22.4) & $28(18.7)$ & $8(14.3)$ & \\
\hline College or over & $36(12.4)$ & 13 (15.3) & 20 (13.3) & $3(5.4)$ & \\
\hline Marital status & & & & & 0.658 \\
\hline Spouse & $233(80.1)$ & $66(77.6)$ & $120(80.0)$ & 47 (83.9) & \\
\hline No spouse & 58 (19.9) & 19 (22.4) & $30(20.0)$ & $9(16.1)$ & \\
\hline Living status & & & & & 0.279 \\
\hline Living with others & 253 (86.9) & $71(83.5)$ & 135 (90.0) & 47 (83.9) & \\
\hline Living alone & $38(13.1)$ & $14(16.5)$ & $15(10.0)$ & $9(16.1)$ & \\
\hline Currently working & & & & & 0.197 \\
\hline Yes & $23(7.9)$ & $10(11.8)$ & $11(7.3)$ & $2(3.6)$ & \\
\hline No & $268(92.1)$ & 75 (88.2) & $139(92.7)$ & $54(96.4)$ & \\
\hline Personal monthly income (Chinese yuan) & & & & & 0.026 \\
\hline$<1000$ & $43(14.8)$ & $7(8.2)$ & $20(13.3)$ & $16(28.6)$ & \\
\hline $1000-1999$ & $50(17.2)$ & $14(16.5)$ & $27(18.0)$ & $9(16.1)$ & \\
\hline 2000-2999 & $100(34.4)$ & $34(40.0)$ & $47(31.3)$ & 19 (33.9) & \\
\hline$\geq 3000$ & $98(33.7)$ & $30(35.3)$ & $56(37.3)$ & $12(21.4)$ & \\
\hline Medical insurance & & & & & 0.034 \\
\hline Urban residential insurance & $79(27.1)$ & $17(20.0)$ & $42(28.0)$ & $20(35.7)$ & \\
\hline Urban employees' insurance & $169(58.1)$ & $56(65.9)$ & $90(60.0)$ & $23(41.1)$ & \\
\hline New rural cooperative medical insurance & $43(14.8)$ & $12(14.1)$ & $18(12.0)$ & $13(23.2)$ & \\
\hline
\end{tabular}

Italic values indicate $\mathrm{P}<0.1$.

with type 2 diabetes. We found the prevalence of prefrailty and frailty were $51.5 \%$ and $19.2 \%$, respectively. Our result was comparable with the Beijing study (the prevalence of frailty was $19.32 \%),{ }^{5}$ however, the Beijing study applied the accumulation of deficits method (Frailty Index $\geq 0.25$ ) to measure frailty among diabetic people aged $\geq 55$ years. By using the Fried frailty phenotype for assessing frailty, the prevalence of frailty in people with diabetes aged 65 and older was $25.0 \%-32.0 \%$, as reported in the American studies. ${ }^{21}{ }^{30}$ In addition, studies conducted in Singapore and Spain showed lower frailty prevalence of $8.2 \%$ and $11.2 \%$, respectively, ${ }^{610}$ but, these two studies also recruited younger diabetic adults (ie, younger than 65 years). The explanation for the wide variation in the prevalence of frailty in community-dwelling diabetic elderly populations is probably related to frailty instrument differences, sample difference and socioeconomic differences among the studies. 
Table 2 Lifestyle and clinical characteristics of the participants by different frailty statuses

\begin{tabular}{|c|c|c|c|c|c|}
\hline \multirow[b]{2}{*}{ Variables } & Total $(n=291)$ & Robust ( $n=85)$ & Prefrail $(n=150)$ & Frail $(n=56)$ & \multirow[b]{2}{*}{$P$ value } \\
\hline & \multicolumn{4}{|c|}{ N (\%)/median (IQR) } & \\
\hline Smoking & & & & & 0.612 \\
\hline Non-smoker & $185(63.6)$ & $54(63.5)$ & $93(62.0)$ & $38(67.9)$ & \\
\hline Ex-smoker & $69(23.7)$ & $17(20.0)$ & $39(26.0)$ & $13(23.2)$ & \\
\hline Current smoker & $37(12.7)$ & $14(16.5)$ & $18(12.0)$ & $5(8.9)$ & \\
\hline Alcohol drinking & & & & & 0.004 \\
\hline Non-drinker & $167(57.4)$ & $50(58.8)$ & $76(50.7)$ & $41(73.2)$ & \\
\hline Ex-drinker & $46(15.8)$ & 7 (8.2) & $30(20.0)$ & $9(16.1)$ & \\
\hline Current drinker & $78(26.8)$ & $28(32.9)$ & $44(29.3)$ & $6(10.7)$ & \\
\hline Sleep duration at night (hours) & & & & & 0.046 \\
\hline$<5$ & $75(25.8)$ & $14(16.5)$ & $39(26.0)$ & $22(39.3)$ & \\
\hline $5-8$ & $192(66.0)$ & $64(75.3)$ & $99(66.0)$ & $29(51.8)$ & \\
\hline$>8$ & $24(8.2)$ & 7 (8.2) & $12(8.0)$ & $5(8.9)$ & \\
\hline Self-rated sleep quality & & & & & 0.065 \\
\hline Very good & $33(11.3)$ & $14(16.5)$ & $17(11.3)$ & $2(3.6)$ & \\
\hline Good & $145(49.8)$ & $44(51.8)$ & 77 (51.3) & $24(42.9)$ & \\
\hline Bad & $89(30.6)$ & $24(28.2)$ & $42(28.0)$ & $23(41.1)$ & \\
\hline Very bad & $24(8.2)$ & $3(3.5)$ & $14(9.3)$ & $7(12.5)$ & \\
\hline Duration of diabetes (years) & $10(4-16)$ & $9(4-16)$ & $11(5-16)$ & $7(4-13)$ & 0.036 \\
\hline No of comorbidities & $5(3-6)$ & $4(3-6)$ & $5(3-6)$ & $5(4-7)$ & 0.030 \\
\hline Polypharmacy & & & & & 0.025 \\
\hline No & $205(70.4)$ & $68(80.0)$ & $104(69.3)$ & 33 (58.9) & \\
\hline Yes & $86(29.6)$ & $17(20.0)$ & $46(30.7)$ & $23(41.1)$ & \\
\hline $\mathrm{BMI}\left(\mathrm{kg} / \mathrm{m}^{2}\right)$ & & & & & 0.321 \\
\hline$<18.5$ & $11(3.8)$ & $0(0)$ & $8(5.3)$ & $3(5.4)$ & \\
\hline $18.5-23.9$ & $127(43.6)$ & $37(43.5)$ & $65(43.3)$ & $25(44.6)$ & \\
\hline $24-27.9$ & $114(39.2)$ & $38(44.7)$ & $58(38.7)$ & $18(32.1)$ & \\
\hline$\geq 28$ & $39(13.4)$ & $10(11.8)$ & $19(12.7)$ & $10(17.9)$ & \\
\hline Waist circumference & & & & & 0.285 \\
\hline Normal & $51(17.5)$ & $11(12.9)$ & $27(18.0)$ & $13(23.2)$ & \\
\hline High & $240(82.5)$ & $74(87.1)$ & $123(82.0)$ & $43(76.8)$ & \\
\hline $\mathrm{HbA1c}(\%)$ & $6.66(5.87-7.47)$ & $6.74(5.96-7.20)$ & $6.48(5.72-7.26)$ & $6.97(5.95-8.42)$ & 0.055 \\
\hline
\end{tabular}

Italic values indicate $\mathrm{P}<0.1$.

$\mathrm{BMI}$, body mass index; HbA1c, glycated haemoglobin.

Alcohol drinking was one predictor of frailty and prefrailty among the diabetic older adults, and the frailty risk was significantly higher among ex-drinkers compared with nondrinkers. This association could be explained by the 'sick quitter' effect. The diabetic older adults in poor health may reduce alcohol consumption or quit drinking, so the ex-drinker group may contain people with previous alcoholism or with a poor health condition. ${ }^{31}$ In our study, it is interesting that current drinking status showed a protective effect $(\mathrm{OR}=0.266, \mathrm{p}=0.055)$ on frailty compared with nondrinkers, although this factor didn't satisfy the statistical significance in the logistic regression. Previous studies indicated alcohol use (especially moderate drinking) had a negative association with physical frailty. ${ }^{32-34}$ Moreover, a recent study demonstrated moderate alcohol consumption may protect against frailty through an anti-inflammatory mechanism, which indicated that $\mathrm{C}$ reactive protein level partially mediated the relationship between moderate alcohol use and physical frailty. ${ }^{35}$

Elevated HbA1c was associated with an increased risk of frailty among community-dwelling diabetic older adults, which was consistent with the previous study in diabetic older people. ${ }^{6}$ Hyperglycaemic could contribute to physical frailty through several potential mechanisms, such as increasing microvascular damage ${ }^{36}$ or causing skeletal muscle mitochondrial dysfunction. ${ }^{37}$ In contrast, Yanagita et al ${ }^{11}$ reported 
Table 3 Malnutrition, depressive symptoms and diabetes self-care behaviours of the participants by different frailty statuses

\begin{tabular}{|c|c|c|c|c|c|c|c|}
\hline \multirow[b]{2}{*}{ Variables } & \multirow{2}{*}{$\begin{array}{l}\text { Possible } \\
\text { range }\end{array}$} & \multirow{2}{*}{$\begin{array}{l}\text { Actual } \\
\text { range }\end{array}$} & $\begin{array}{l}\text { Total } \\
(\mathrm{n}=291)\end{array}$ & $\begin{array}{l}\text { Robust } \\
(\mathrm{n}=85)\end{array}$ & $\begin{array}{l}\text { Pre-frail } \\
(n=150)\end{array}$ & Frail $(n=56)$ & \multirow[b]{2}{*}{$P$ value } \\
\hline & & & \multicolumn{4}{|c|}{ N (\%)/median (IQR) } & \\
\hline Malnutrition risk/malnutrition & & & & & & & $<0.001$ \\
\hline No & & & 189 (64.9) & $76(89.4)$ & $96(64.0)$ & $17(30.4)$ & \\
\hline Yes & & & $102(35.1)$ & $9(10.6)$ & $54(36.0)$ & $39(69.6)$ & \\
\hline GDS-15 score & $0-15$ & $0-15$ & $3(1-5)$ & $1(0-3)$ & $3(1-5)$ & $5(4-8)$ & $<0.001$ \\
\hline \multicolumn{8}{|l|}{ SDSCA score } \\
\hline General diet score & $0-14$ & $0-14$ & $14(10-14)$ & $14(10-14)$ & $14(10-14)$ & $14(10-14)$ & 0.465 \\
\hline Specific diet score & $0-14$ & $0-14$ & $8(7-12)$ & $10(7-13)$ & $7(7-12)$ & $7(7-12)$ & 0.131 \\
\hline Exercise score & $0-14$ & $0-14$ & $7(7-14)$ & $14(7-14)$ & $7(7-14)$ & $7(0-7)$ & $<0.001$ \\
\hline Blood-glucose testing score & $0-14$ & $0-14$ & $0(0-2)$ & $0(0-2)$ & $0(0-2)$ & $0(0-1)$ & 0.183 \\
\hline Foot care score & $0-14$ & $0-14$ & $0(0-7)$ & $0(0-7)$ & $0(0-7)$ & $0(0-0)$ & 0.007 \\
\hline Medication care score & $0-7$ & $0-7$ & $7(7-7)$ & $7(7-7)$ & $7(7-7)$ & $7(7-7)$ & 0.060 \\
\hline
\end{tabular}

Italic values indicate $\mathrm{P}<0.1$.

GDS-15, geriatric depression scale-15; SDSCA, summary of diabetes self-care activities.

low level of $\mathrm{HbAlc}$ was associated with frailty measured by the Clinical Frailty Scale among diabetic older adults. Zaslavsky et $a l^{38}$ found a U-shaped relationship between glucose levels and physical frailty in older adults with diabetes, with the lowest risk of frailty at HbA1c levels of 7.6\%. Overall, poor glucose control with hyperglycaemic or hypoglycaemic may increase the risk of frailty. Therefore, optimal glycaemic control needs to be individually determined for older adults with type 2 diabetes. ${ }^{39}$ The global guideline for managing type 2 diabetes in older adults recommended that an HbAlc target up to $8.5 \%$ may be appropriate for frail diabetic elderly persons with functional dependency. ${ }^{40}$ Recently, an international position statement on the management of frailty in diabetes mellitus patients recommended an HbAlc target range of $7.0 \%-8.0 \%$ for mild to moderate frail diabetic older adults, and $7.5 \%-8.5 \%$ for those with severe frailty. ${ }^{41}$
Malnutrition led to prefrailty and frailty among communitydwelling older adults with type 2 diabetes, which was comparable with the findings of a Spanish study. ${ }^{12}$ In the current study, $35.1 \%$ of our participants were at risk for malnutrition or were malnourished, and $52.6 \%$ of them were overweight or obese. However, 39 (38.2\%) of the participants who had malnutrition risk or were malnourished in this study were classified as either overweight or obese. This result suggests that the diabetic elderly can suffer from malnutrition status even if they are overweight or obese. Malnutrition is prevalent in diabetic older adults ${ }^{42}{ }^{43}$ due to various reasons, such as ageing-related appetite reductions, swallowing difficulties, limited mobility and overly dietary restrictions. ${ }^{44}$ We found that $45.4 \%$ of the diabetic older adults scored 0 points on the item of protein intake in this study, indicating that those people might have insufficient protein intake. Although

Table 4 Logistic regression model of predictors for prefrailty and frailty

\begin{tabular}{|c|c|c|c|c|c|c|}
\hline & \multicolumn{3}{|c|}{ Pre-frail } & \multicolumn{3}{|l|}{ Frail } \\
\hline & OR & $95 \% \mathrm{Cl}$ & $P$ value & OR & $95 \% \mathrm{Cl}$ & $P$ value \\
\hline \multicolumn{7}{|l|}{ Alcohol Drinking } \\
\hline Ex-drinker & 3.664 & 1.260 to 10.653 & 0.017 & 4.461 & 1.079 to 18.438 & 0.039 \\
\hline Current drinker & 1.416 & 0.680 to 2.950 & 0.353 & 0.266 & 0.069 to 1.026 & 0.055 \\
\hline Non-drinker & 1 & - & - & 1 & - & - \\
\hline $\mathrm{HbA1c}$ & 0.830 & 0.644 to 1.071 & 0.152 & 1.434 & 1.045 to 1.968 & 0.026 \\
\hline \multicolumn{7}{|c|}{ Malnutrition risk/malnutrition } \\
\hline Yes & 2.806 & 1.133 to 6.950 & 0.026 & 8.062 & 2.470 to 26.317 & 0.001 \\
\hline No & 1 & - & - & 1 & - & - \\
\hline GDS-15 score & 1.285 & 1.087 to 1.520 & 0.003 & 1.438 & 1.166 to 1.773 & 0.001 \\
\hline Exercise score & 0.906 & 0.843 to 0.974 & 0.008 & 0.796 & 0.716 to 0.884 & $<0.001$ \\
\hline
\end{tabular}

Italic values indicate $\mathrm{P}<0.05$.

GDS-15, Geriatric Depression Scale-15; HbA1c, glycated haemoglobin. 
malnutrition and physical frailty share some common screening items and physiology, they are not interchangeable syndromes and community-dwelling diabetic older people with malnutrition were more prone to be physically frail. Screening the nutritional status of diabetic older adults and providing them with appropriate dietary instructions would be an effective method for preventing physical frailty within this population.

Consistent with previous studies among older populations ${ }^{1516}$ this study highlighted the significant impact of depressive symptoms on prefrailty and frailty among the diabetic elderly. Recent evidence showed a reciprocal interaction between depression and frailty in older adults. ${ }^{16}$ Depression contributes to physical frailty due to the decrease in physical activities or weight loss, and in turn, physical frailty may cause functional dependence or disability, thus leading to depression. Diabetes can contribute to depression, which is a common condition in people with type 2 diabetes, especially in the elderly. ${ }^{456}$ Therefore, there is an urgent need for appropriate management of depressive symptoms in elderly diabetic adults in order to help slow the progression of physical frailty in this population.

We found exercise behaviour was a protective factor for frailty among community-dwelling diabetic older adults. A higher score of exercise behaviour was associated with a lower risk of prefrailty and frailty. Exercise can help reduce frailty through mechanisms of decreasing muscle inflammation, promoting anabolism and increasing muscle protein synthesis. ${ }^{47}$ Education programmes for exercise training have shown to be effective at improving frailty in the elderly. ${ }^{48}$ Pariser $e t a t^{49}$ conducted a diabetes self-management education programme composed of 10 weeks of aerobic and resistance exercise training, which effectively reduced HbAlc and frailty in diabetic older adults. In addition, the three different frailty groups (ie, robust, prefrail and frail) differed significantly in terms of medication care and foot self-care behaviours in this study. The association between medication care behaviour and frailty may be explained by the fact that adherence to medication is directly associated with the control of blood glucose, which has an impact on the progression of frailty. The association between foot self-care behaviour and frailty could be explained by the observation that the participants with a higher score on foot care were more likely to be active in self-management for complications prevention and concerned about their own health, contributing to a reduced risk of frailty.

This study has several limitations. First, this study is a crosssectional study, therefore, the causal relationship of the associated factors with frailty could not be established. Second, information such as the older adults' physical activities and self-care behaviours were self-reported, so it may be subject to potential recall bias. Third, we excluded older adults who could not walk independently, as well as those with severe vision and hearing problems, so findings may not be generalisable to a more heterogeneous population. Fourth, the data collected from one city would likely not reflect the nation-wide prevalence of frailty. Fifth, information such as the amount of alcohol consumed weekly for current drinkers and the date of drinking cessation, as well as the amount of previous alcohol consumption for ex-drinkers was not collected in this study. Future studies on the relationship between alcohol consumption and frailty in this population are warranted. Finally, future studies should explore the effects of clinical and behavioural factors on frailty among community-dwelling diabetic older adults using a prospective longitudinal design and a larger sample size.

\section{CONCLUSIONS}

Older adults with type 2 diabetes are at a high risk of frailty in Chinese elderly populations. Being an ex-drinker, having a higher level of HbAlc, experiencing malnutrition risk/ malnutrition, and suffering from depressive symptoms were risk factors of frailty among the community-dwelling diabetic older adults; exercise self-care behaviour was found to be a protective factor for frailty. The findings of this study could help guide future studies to implement targeted and suitable interventions for preventing frailty among communitydwelling diabetic older adults.

Acknowledgements The authors wish to thank the administrators, public health nurses, and physicians in the two community health centres for assisting with data collection. We also want to thank the community members for participating in this study.

Contributors LK, JL and JM designed the study. LK, HZ and QW collected and managed the data. LK and JF completed the data analysis. LK and JL drafted the manuscript. JB checked and revised the manuscript. All the authors read and approved the final manuscript.

Funding This study was supported by National Natural Science Foundation of China (No. 71503088).

Competing interests None declared.

Patient consent for publication Not required.

Ethics approval Ethical Approval was obtained from the Medical Ethics Committee of Huazhong University and Science and Technology (No. 2019-S941) prior to data collection.

Provenance and peer review Not commissioned; externally peer reviewed.

Data availability statement Data are available on reasonable request. All data relevant to the study are included in the article.

Open access This is an open access article distributed in accordance with the Creative Commons Attribution Non Commercial (CC BY-NC 4.0) license, which permits others to distribute, remix, adapt, build upon this work non-commercially, and license their derivative works on different terms, provided the original work is properly cited, appropriate credit is given, any changes made indicated, and the use is non-commercial. See: http://creativecommons.org/licenses/by-nc/4.0/.

\section{ORCID iDs}

Linglin Kong http://orcid.org/0000-0002-5103-4409

Jing Mao http://orcid.org/0000-0001-6353-9992

\section{REFERENCES}

1 International Diabetes Federation. IDF diabetes atlas. 9th edition, 2019. Available: https://www.diabetesatlas.org

2 Wang L, Gao P, Zhang M, et al. Prevalence and ethnic pattern of diabetes and prediabetes in China in 2013. JAMA 2017;317:2515-23.

3 Assar ME, Laosa O, Rodríguez Mañas L. Diabetes and frailty. Curr Opin Clin Nutr Metab Care 2019;22:52-7.

4 Morley JE, Vellas B, van Kan GA, et al. Frailty consensus: a call to action. J Am Med Dir Assoc 2013;14:392-7.

5 Chhetri JK, Zheng Z, Xu X, et al. The prevalence and incidence of frailty in Pre-diabetic and diabetic community-dwelling older population: results from Beijing longitudinal study of aging II (BLSAII). BMC Geriatr 2017;17:47. 
6 García-Esquinas E, Graciani A, Guallar-Castillón P, et al. Diabetes and risk of frailty and its potential mechanisms: a prospective cohort study of older adults. J Am Med Dir Assoc 2015;16:748-54.

7 Sinclair AJ, Abdelhafiz AH, Rodríguez-Mañas L, Frailty R-ML. Frailty and sarcopenia - newly emerging and high impact complications of diabetes. J Diabetes Complications 2017;31:1465-73.

8 Umegaki $\mathrm{H}$. Sarcopenia and frailty in older patients with diabetes mellitus. Geriatr Gerontol Int 2016;16:293-9.

9 Chao C-T, Wang J, Chien K-L, et al. Both pre-frailty and frailty increase healthcare utilization and adverse health outcomes in patients with type 2 diabetes mellitus. Cardiovasc Diabetol 2018; $17: 130$.

10 Thein FS, Li Y, Nyunt MSZ, et al. Physical frailty and cognitive impairment is associated with diabetes and adversely impact functional status and mortality. Postgrad Med 2018;130:561-7.

11 Yanagita I, Fujihara Y, Eda T, et al. Low glycated hemoglobin level is associated with severity of frailty in Japanese elderly diabetes patients. J Diabetes Investig 2018;9:419-25.

12 Casals C, Casals Sánchez JL, Suárez Cadenas E, et al. [Frailty in older adults with type 2 diabetes mellitus and its relation with glucemic control, lipid profile, blood pressure, balance, disability grade and nutritional status]. Nutr Hosp 2018;35:820-6.

13 Verlaan S, Ligthart-Melis GC, Wijers SLJ, et al. High prevalence of physical frailty among community-dwelling malnourished older Adults-A systematic review and meta-analysis. J Am Med Dir Assoc 2017:18:374-82.

14 Wei K, Nyunt MSZ, Gao Q, et al. Frailty and malnutrition: related and distinct syndrome prevalence and association among communitydwelling older adults: Singapore longitudinal ageing studies. J Am Med Dir Assoc 2017;18:1019-28.

15 Aprahamian I, Suemoto CK, Lin SM, et al. Depression is associated with self-rated frailty in older adults from an outpatient clinic: a prospective study. Int Psychogeriatr 2019;31:425-34.

16 Soysal P, Veronese N, Thompson T, et al. Relationship between depression and frailty in older adults: a systematic review and metaanalysis. Ageing Res Rev 2017;36:78-87.

17 Toobert DJ, Hampson SE, Glasgow RE. The summary of diabetes self-care activities measure: results from 7 studies and a revised scale. Diabetes Care 2000;23:943-50.

18 Cai C, Jia WP. Community healthcare for diabetes in China (in Chinese). Scientia Sinica(Vitae) 2018;48:820-6.

19 Pourhoseingholi MA, Vahedi M, Rahimzadeh M. Sample size calculation in medical studies. Gastroenterol Hepatol Bed Bench 2013;6:14-17.

20 Zhou B-F, Cooperative Meta-Analysis Group of the Working Group on Obesity in China. Predictive values of body mass index and waist circumference for risk factors of certain related diseases in Chinese adults--study on optimal cut-off points of body mass index and waist circumference in Chinese adults. Biomed Environ Sci 2002;15:83-96.

21 Fried LP, Tangen CM, Walston J, et al. Frailty in older adults: evidence for a phenotype. J Gerontol A Biol Sci Med Sci 2001;56:M146-57.

22 Auyeung TW, Lee JSW, Leung J, et al. The selection of a screening test for frailty identification in community-dwelling older adults. $J$ Nutr Health Aging 2014;18:199-203.

23 Wu C-Y, Su T-P, Fang C-L, et al. Sleep quality among communitydwelling elderly people and its demographic, mental, and physical correlates. J Chin Med Assoc 2012;75:75-80.

24 Guigoz Y, Vellas B, Garry PJ. Assessing the nutritional status of the elderly: the mini nutritional assessment as part of the geriatric evaluation. Nutr Rev 1996;54:S59-65.

25 Han Y, Li S, Zheng Y. Predictors of nutritional status among community-dwelling older adults in Wuhan, China. Public Health Nutr 2009;12:1189-96.

26 Sheikh JI, Yesavage JA, Scale GD. Gds): recent evidence and development of a shorter version. Clinical Gerontologist 1986;5:165-73.
27 H-cB L, Chiu HFK, Kowk WY. Chinese elderly and the GDS short form: a preliminary study. Clinical Gerontologist 1993;14:37-42.

28 Wan $Q Q$, Shang SM, Lai XB. Study on the reliability and validity of summary of diabetes self-care activities for type 2 diabetes patients (in Chinese). Chin J Prac Nurs 2008;24:26-7.

29 Li ET, Tang EK, Wong CY, et al. Predicting stature from knee height in Chinese elderly subjects. Asia Pac J Clin Nutr 2000;9:252-5.

30 Ottenbacher KJ, Graham JE, Al Snih S, et al. Mexican Americans and frailty: findings from the Hispanic established populations epidemiologic studies of the elderly. Am J Public Health 2009;99:673-9.

31 Kojima G, Liljas A, lliffe S, et al. A systematic review and metaanalysis of prospective associations between alcohol consumption and incident frailty. Age Ageing 2018;47:26-34.

32 Ortolá R, García-Esquinas E, León-Muñoz LM, et al. Patterns of alcohol consumption and risk of frailty in community-dwelling older adults. J Gerontol A Biol Sci Med Sci 2016;71:251-8.

33 Shah M, Paulson D, Nguyen V. Alcohol use and frailty risk among older adults over 12 years: the health and retirement study. Clin Gerontol 2018:41:315-25.

34 Kojima G, Jivraj S, lliffe S, et al. Alcohol consumption and risk of incident frailty: the English longitudinal study of aging. J Am Med Dir Assoc 2019;20:725-9.

35 Shah M, Paulson D. C-Reactive protein level partially mediates the relationship between moderate alcohol use and frailty: the health and retirement study. Age Ageing 2016;45:874-8.

36 Sheetz MJ, King GL. Molecular understanding of hyperglycemia's adverse effects for diabetic complications. JAMA 2002;288:2579-88.

37 Phielix E, Schrauwen-Hinderling VB, Mensink M, et al. Lower intrinsic ADP-stimulated mitochondrial respiration underlies in vivo mitochondrial dysfunction in muscle of male type 2 diabetic patients. Diabetes 2008;57:2943-9.

38 Zaslavsky O, Walker RL, Crane PK, et al. Glucose levels and risk of frailty. J Gerontol A Biol Sci Med Sci 2016;71:1223-9.

39 Mathur S, Zammitt NN, Frier BM. Optimal glycaemic control in elderly people with type 2 diabetes: what does the evidence say? Drug Saf 2015;38:17-32.

40 International Diabetes Federation. Managing older people with type 2 diabetes: global guideline, 2013. Available: https://www.idf.org/ e-library/guidelines/78-global-guideline-for-managing-older-peoplewith-type-2-diabetes.html

41 Sinclair AJ, Abdelhafiz A, Dunning T, et al. An international position statement on the management of frailty in diabetes mellitus: summary of recommendations 2017. J Frailty Aging 2018;7:10-20.

42 Liu G-X, Chen Y, Yang Y-X, et al. Pilot study of the Mini Nutritional Assessment on predicting outcomes in older adults with type 2 diabetes. Geriatr Gerontol Int 2017;17:2485-92.

43 Vischer UM, Perrenoud L, Genet C, et al. The high prevalence of malnutrition in elderly diabetic patients: implications for anti-diabetic drug treatments. Diabet Med 2010;27:918-24.

44 McClinchy J. Dietary management of older people with diabetes. $\mathrm{Br}$ J Community Nurs 2018;23:248-51.

45 Park M, Reynolds CF. Depression among older adults with diabetes mellitus. Clin Geriatr Med 2015;31:117-37.

46 Darwish L, Beroncal E, Sison MV, et al. Depression in people with type 2 diabetes: current perspectives. Diabetes Metab Syndr Obes 2018:11:333-43.

47 Aguirre LE, Villareal DT. Physical exercise as therapy for frailty. Nestle Nutr Inst Workshop Ser 2015;83:83-92.

48 de Labra C, Guimaraes-Pinheiro C, Maseda A, et al. Effects of physical exercise interventions in frail older adults: a systematic review of randomized controlled trials. BMC Geriatr 2015;15:154.

49 Pariser G, Hager K, Gillette P, et al. Active steps for diabetes: a community-campus partnership addressing frailty and diabetes. Diabetes Educ 2014;40:60-7. 